\title{
Delay in treatment intensification increases the risks of cardiovascular events in patients with type 2 diabetes
}

\author{
Sanjoy K Paul ${ }^{1 *}{ }^{*}$, Kerenaftali Klein ${ }^{1}$, Brian L Thorsted ${ }^{2}$, Michael L Wolden ${ }^{2}$ and Kamlesh Khunti ${ }^{3+}$
}

\begin{abstract}
Background: The aim of the study was to evaluate the effect of delay in treatment intensification (IT; clinical inertia) in conjunction with glycaemic burden on the risk of macrovascular events (CVE) in type 2 diabetes (T2DM) patients.

Methods: A retrospective cohort study was carried out using United Kingdom Clinical Practice Research Datalink, including T2DM patients diagnosed from 1990 with follow-up data available until 2012.

Results: In the cohort of 105,477 patients mean $\mathrm{HbA1c}$ was $8.1 \%$ (65 mmol/mol) at diagnosis, $11 \%$ had a history of cardiovascular disease, and $7.1 \%$ experienced at least one CVE during 5.3 years of median follow-up. In patients with $\mathrm{HbA} 1 \mathrm{c}$ consistently above $7 / 7.5 \%(53 / 58 \mathrm{mmol} / \mathrm{mol}, \mathrm{n}=23,101 / 11,281)$ during 2 years post diagnosis, 26/22\% never received any IT. Compared to patients with $\mathrm{HbA} 1 \mathrm{c}<7 \%(<53 \mathrm{mmol} / \mathrm{mol})$, in patients with $\mathrm{HbAlc} \geq 7 \%$ ( $\geq 53 \mathrm{mmol} /$ mol), a 1 year delay in receiving IT was associated with significantly increased risk of MI, stroke, HF and composite CVE by $67 \%$ (HR Cl: 1.39, 2.01), 51\% (HR Cl: 1.25, 1.83), 64\% (HR Cl: 1.40, 1.91) and 62\% (HR Cl: 1.46, 1.80) respectively. One year delay in IT in interaction with $\mathrm{HbA} 1 \mathrm{c}$ above $7.5 \%(58 \mathrm{mmol} / \mathrm{mol})$ was also associated with similar increased risk of CVE.

Conclusions: Among patients with newly diagnosed T2DM, 22\% remained under poor glycaemic control over 2 years, and 26\% never received IT. Delay in IT by 1 year in conjunction with poor glycaemic control significantly increased the risk of $\mathrm{MI}, \mathrm{HF}$, stroke and composite CVE.
\end{abstract}

Keywords: Type 2 diabetes, Delay in treatment intensification, Cardiovascular risk, Longitudinal analysis, Clinical inertia

\section{Background}

Currently $8.3 \%$ of adults worldwide are estimated to have diabetes [1]. The risk of cardiovascular complications has been related to glycaemia in patients with type 2 diabetes mellitus (T2DM). Randomised controlled trials have conclusively demonstrated that the risk of microvascular complications can be reduced by intensive glycaemic control in patients with T2DM [2-4]. However, there are controversies regarding the benefits of intensive glucose control [HbA1c $<7 \%(53 \mathrm{mmol} / \mathrm{mol})]$ on

\footnotetext{
*Correspondence: Sanjoy.Paul@qimrberghofer.edu.au

${ }^{\dagger}$ Sanjoy K Paul and Kamlesh Khunti contributed equally to this work

${ }^{1}$ Clinical Trials and Biostatistics Unit, QIMR Berghofer Medical Research

Institute, 300 Herston Road, Herston, Brisbane, QLD 4006, Australia

Full list of author information is available at the end of the article
}

macrovascular events (CVE), as some of the large trials have failed to show any significant reduction in CVE [4, 5]. The ACCORD trial failed to show any benefit of intensive glucose lowering on $\mathrm{CVE}$, although the haemoglobin A1c (HbA1c) level was reduced to $6.4 \%(46.4 \mathrm{mmol} / \mathrm{mol})$ in the intensive treatment arm compared to HbA1c level of $7.5 \%(58.5 \mathrm{mmol} / \mathrm{mol})$ in the standard treatment arm [6]. The primary care based randomised trial ADDITION reported only a small, non-significant reduction in the incidence of $\mathrm{CVE}$ and death associated with early intensive management of the disease [7]. However, the UKPDS Post Trial Monitoring Study demonstrated that intensive glucose control starting at the time of diagnosis of diabetes could be associated with a significantly decreased risk of myocardial infarction (MI) and death from any 
cause [8]. Also, the meta-analysis of four large cardiovascular outcome trials in patients with T2DM revealed that tighter glycaemic control was associated with 9\% reduction in risk of major cardiovascular events [9]. However, tight glycaemic control was not associated with reduced mortality.

Glycaemic management in patients with T2DM has become increasingly complex, and in some cases controversial, with a widening classes of pharmacological agents now available [10-12]. Based on the individual characteristics of the patients, step-wise life-style and pharmacological approaches have been suggested by international guidelines for better glycaemic management in patients with T2DM [13-15].

The American Diabetes Association guidelines recommend starting metformin alongside lifestyle modifications at diagnosis, aiming for a HbA1c target of $<7 \%$ ( $<53 \mathrm{mmol} / \mathrm{mol}$ ) [15]. Additional oral anti-diabetes drugs (OADs) may be added if the HbA1c continues to remain above the recommended target of $6.5 \%(48 \mathrm{mmol} / \mathrm{mol})$, and if $\mathrm{HbA} 1 \mathrm{c}$ reaches $\geq 7.5 \%(\geq 58 \mathrm{mmol} / \mathrm{mol})$, further intensification including the use of insulin is recommended [13, 16]. The intensification of anti-diabetes therapies also depends on individual patient's characteristics including age, co-morbidities, the risk of hypoglycaemia, and provider and patient's preferences [13]. However, a high proportion of people with T2DM fail to reach the recommended glycaemic targets for a considerable period of time post diagnosis of diabetes (glycaemic burden) [17-21]. Among those with poor glycaemic control [HbAlc $\geq 7 \%(\geq 53 \mathrm{mmol} / \mathrm{mol})]$, an overwhelmingly large proportion of people do not receive intensified treatment in time. This "delay in treatment intensification", also termed as clinical inertia, has been discussed by some studies [17-21]. A recent study based on 80,000 patients with T2DM from the United Kingdom primary care system reported that the average time to intensification to two oral anti-diabetes drugs (OADs) from one OAD among patients with HbA1c above $7 \%(53 \mathrm{mmol} /$ mol) was about 3 years [21]. The aspects of glycaemic variability and treatment quality indicators and their association with macrovascular risk were evaluated by Penno et al. [22] and Sidorenkov et al. [23], respectively. Asche et al. [24] evaluated the clinical and economic benefits of early intensification of treatment with insulin in patients with T2DM, and reported significant benefits in terms of glycaemic management.

While studies have reported the real-world scenario in terms of intensification of treatments for hyperglycaemia among patients with poorly controlled glycaemia, the possible effect of delay in treatment intensification in conjunction with the dynamic changes in glycaemic control on the vascular risk factors, has not yet been studied to the best of our knowledge. The aims of this retrospective cohort study were to (1) explore the glycaemic control over 2 years post diagnosis of diabetes in relation to treatment intensification, and (2) evaluate the effect of the delay in treatment intensification in conjunction with guideline recommended glycaemic control on the of risk of MI, heart failure (HF), stroke, and composite of these three CVE.

\section{Methods}

\section{Data source}

The data for this retrospective cohort study was extracted from the United Kingdom Clinical Practice Research Datalink (CPRD), which is representative of the United Kingdom general population [25-27]. All information collected in the CPRD has been subjected to validation studies and been proven to contain consistent and highquality data $[26,28]$.

Data were extracted from CPRD with a first identifiable record of diagnosis code for T2DM covering period from January 1990 with follow-up data to December 2012, with maximum possible follow-up time of 23 years. The confirmation for the incident diagnosis of T2DM was based on Read/Oxford Medical Information System Codes [29], supported by rigorous classification techniques [30, 31].

The following information was extracted: age, gender, smoking status (defined as current, ex or never smoker), body mass index (BMI), HbA1c, history of cardiovascular and renal diseases before the diagnosis of diabetes, and clinical events during follow-up, including cardiovascular diseases (MI, HF, stroke and coronary heart diseases), atherosclerosis, diabetic neuropathy, and renal complications, along with dates of events. Detailed information on OADs and insulin along with anti-hypertensive and cardio-protective medications (including use of $\mathrm{ACE}$ inhibitor, Beta Blocker, Statin and other concomitant medications) were obtained from prescriptions along with dates. The study cohort $(\mathrm{n}=105,477)$ was based under the conditions: (1) read code for T2DM and at least two prescriptions for any OAD or insulin (as recorded in the primary care system) within 6 months of date of diagnosis of T2DM (prescription provided and recorded by general practice), (2) age $\geq 18$ years at index date (date of diagnosis of T2DM), (3) complete information on age, sex, smoking status at index date, (4) a measure of HbA1c available within a 3-month window of the index date (HbAlc measured within 3 months before the date of first diagnosis code recorded), (5) minimum 2 years of follow-up before the occurrence of any CVE post diagnosis of diabetes, (6) availability of dates of prescriptions longitudinally for anti-diabetes drugs, (7) completeness of dates for all CVEs during post diagnosis follow-up. Choice of this cohort of patients with new diagnosis of 
T2DM ensures censoring for CVE in the first 2 years post diagnosis of diabetes, and 2 years window for treatment intensification with the availability of data on glycaemic control.

Clinical comorbidities prior to diagnosis of diabetes, including cardiovascular and renal diseases, were coded as present if they were diagnosed at any point between entry into CPRD and the index date. The clinical and laboratory measures were arranged longitudinally on the basis of 6-monthly windows. The 6-month windows were defined progressive from the index date, with 180 days immediately post index date defining first follow-up window.

The study was approved by the Independent Scientific Advisory Committee (Protocol no 13_062R2).

\section{Statistical methods}

Treatment intensification (IT) was defined in two ways: (1) adding a second OAD (OAD2) or (2) adding insulin to the first OAD (OAD + INS). Time to IT was calculated by subtracting the index date from the first date of IT. The subjects who did not belong to OAD2 or OAD + INS groups were defined as "never intensified" category.

Missing HbA1c data (about 9\% missing over 24 months post diagnosis) at 6-monthly window were imputed using multiple imputation technique (Bayesian MCMC approach) $[32,33]$. The consistency of the imputed data with the original HbA1c data was verified. Adequate checks were in place to ensure that patients were not lost to follow-up for imputing missing values during 2 years post diagnosis. Patients were categorized by HbA1c below or above $7 \%(53 \mathrm{mmol} / \mathrm{mol})$ and $7.5 \%(58 \mathrm{mmol} /$ mol) consistently over 1 and 2 years post diagnosis to identify poor glycaemic control.

The composite CVE was based on the occurrence of either of MI, HF or stroke. To evaluate the effect of delay in IT on events, only those vascular events were considered which occurred after the time of first intensification (OAD2 or OAD + INS), apart from the condition of no occurrence of CVE during first 2 years post diagnosis of diabetes (to ensure minimum exposure time of 2 years). In this context, the "time to" individual events were calculated by subtracting the first event date (as appropriate) from the date when intensified treatment started. The analysis set for cardiovascular risk analysis included only those belonging to OAD2 or OAD + INS categories.

As time to treatment intensification (TTIT) is highly likely to be interacted with the glycaemic control over time, the interaction of TTIT with HbA1c categories over time was evaluated in terms of cardiovascular risks. To evaluate the interaction effect we constructed the following four groups: reference group-TTIT $<12$ months and HbA1c $<7 \%(<53 \mathrm{mmol} / \mathrm{mol}$ ) (consistently $<7 \%$ over
12 months post diagnosis); group $1-$ TTIT $\geq 12$ months and $\mathrm{HbA} 1 \mathrm{c} \geq 7 \% \quad(\geq 53 \mathrm{mmol} / \mathrm{mol})$; group $2-$ TTIT $<12$ months and HbA1c $\geq 7 \%$ ( $\geq 53 \mathrm{mmol} / \mathrm{mol})$; group 3 -TTIT $\geq 12$ months and HbA1c $<7 \%$ ( $<53 \mathrm{mmol} / \mathrm{mol})$. The Group 1 reflects both clinical inertia and glycaemic burden together, while Group 2 reflects only the glycaemic burden. Multivariate Cox regression models were used to evaluate the effect of delay in IT in conjunction with poor glycaemic control consistently over 1 year post diagnosis, adjusting for age and HbAlc at diagnosis of diabetes, sex, smoking status, use of cardio-protective medications (Statin, ACE/ARB and Beta Blocker), any renal disease during follow-up, and the history of CVD before diagnosis of diabetes. The proportionality assumption in the models was tested, and stratified models were fitted with the quartiles of age at diagnosis of diabetes as the stratifying factor. Separate analyses were also conducted for patients with and without the history of CVE. Additional multivariate Cox regression models were also fitted with incomplete information on BMI, systolic blood pressure, LDL-cholesterol and total cholesterol at diagnosis (about 62,000 patients).

To evaluate the possible lack of treatment intensification in older patients (age $>70$ years at diagnosis of diabetes) and in patients with history of CVD and renal diseases, logistic regression models were fitted. The odds ratios (OR) and their 95\% confidence intervals were presented. The likelihood of receiving intensified treatment in poorly controlled patients by categories based on time windows of diagnosis was also evaluated.

\section{Results}

In the cohort of 105,477 patients: $56 \%$ were male, $62 \%$ current or ex-smokers, mean (SD) age at diagnosis of 61 (13) years, and $11 \%(\mathrm{n}=11,955)$ had history of CVD before the diagnosis of diabetes (Table 1). The distribution of HbA1c was highly skewed at diagnosis of diabetes, with mean (SD) and median (IQR) levels of $8.1(2.2) \%$ $(65 \mathrm{mmol} / \mathrm{mol})$ and $7.4(6.5,9.3) \%[57(48,78) \mathrm{mmol} /$ mol], respectively, and $62 \%$ patients had HbA1c $\geq 7 \%$ $(\geq 53 \mathrm{mmol} / \mathrm{mol}$ ) at diagnosis.

In the study cohort 48,036 patients (46\%) received intensified treatment (IT) during follow-up. Among those who received IT, the proportions with time to IT (TTIT) $<6$ months, <1 year, and $<2$ years were 26,36 , and $53 \%$, respectively. The overall median/mean time (months) to receiving IT, at least 2 OADs (2OADs) and at least 3 anti-diabetes drugs (3ADDs) were 21/29, 22/29, and $43 / 48$, respectively.

\section{The clinical inertia and glycaemic burden}

The 6-monthly trajectory of HbA1c over 2 years post diagnosis of diabetes, by the categories of TTIT, is 
Table 1 Descriptive statistics on study parameters at diagnosis of diabetes and at follow-up

\begin{tabular}{|c|c|c|c|}
\hline & Without previous CVD & With previous CVD & All patients \\
\hline$n$ & 93,522 & 11,955 & 105,477 \\
\hline Male ${ }^{a}$ & $50,963(55)$ & $7,609(64)$ & $58,572(56)$ \\
\hline Age at diagnosis (years) & $60(13)$ & $68(11)$ & $61(13)$ \\
\hline \multicolumn{4}{|l|}{ Patients by year of diagnosis ${ }^{\mathrm{a}}$} \\
\hline 1990-December 1999 & $1,893(2)$ & $201(2)$ & $2,094(2)$ \\
\hline January 2000-December 2004 & $28,551(31)$ & $3,741(31)$ & $32,292(31)$ \\
\hline January 2005-December 2009 & $52,317(56)$ & $6,647(56)$ & $58,964(56)$ \\
\hline January 2010 & $10,761(12)$ & $1,366(11)$ & $12,127(12)$ \\
\hline \multicolumn{4}{|l|}{ Smoking status ${ }^{\mathrm{a}}$} \\
\hline Current smoking & $17,545(19)$ & $2,022(17)$ & $19,567(19)$ \\
\hline Ex-smoking & $39,016(42)$ & $6,922(58)$ & $45,938(44)$ \\
\hline BMI at diagnosis $\left(\mathrm{kg} / \mathrm{m}^{2}\right)^{\mathrm{b}}$ & $32(7)$ & $31(6)$ & $32(7)$ \\
\hline $\mathrm{HbA} 1 \mathrm{c}$ at diagnosis $(\%)^{\mathrm{b}}$ & $8.2(2.2)$ & $7.8(2.0)$ & $8.1(2.2)$ \\
\hline $\mathrm{HbA} 1 \mathrm{c}$ at diagnosis $(\mathrm{mmol} / \mathrm{mol})^{\mathrm{b}}$ & 66 & 62 & 65 \\
\hline \multicolumn{4}{|l|}{$\mathrm{HbA} 1 \mathrm{C} \geq 7 \%$ ( $\geq 53 \mathrm{mmol} / \mathrm{mol}$ ) post diagnosis ${ }^{\mathrm{a}}$} \\
\hline Consistently during 1 year post diagnosis & $27,375(29)$ & $3,096(26)$ & $30,471(29)$ \\
\hline Consistently during 2 years post diagnosis & $20,856(22)$ & $2,245(19)$ & $23,101(22)$ \\
\hline \multicolumn{4}{|l|}{ CVE during follow-up ${ }^{\mathrm{a}}$} \\
\hline $\mathrm{Ml}$ & $1,876(2.01)$ & $569(4.76)$ & $2,445(2.32)$ \\
\hline $\mathrm{HF}$ & $2,295(2.45)$ & $898(7.51)$ & $3,193(3.03)$ \\
\hline Stroke & $1,782(1.91)$ & $485(4.06)$ & $2,267(2.15)$ \\
\hline Any CVE & $4,293(6.64)$ & $1,833(8.39)$ & $6,126(7.08)$ \\
\hline \multicolumn{4}{|l|}{ Renal disease $\mathrm{a}^{\mathrm{a}}$} \\
\hline Before diagnosis & $16,630(17.78)$ & $3,116(26.06)$ & $19,746(18.72)$ \\
\hline Post diagnosis & $25,662(27.44)$ & 4,601 (38.49) & $30,263(28.69)$ \\
\hline Duration of follow-up (years) ${ }^{c}$ & $5.0(3.4,7.2)$ & $5.4(3.5,7.7)$ & $5.3(3.5,7.7)$ \\
\hline \multicolumn{4}{|l|}{ Medication $^{\mathrm{a}}$} \\
\hline $2 \mathrm{OADs}$ & $41,696(45)$ & $4,515(38)$ & $46,211(44)$ \\
\hline Insulin & $8,778(9)$ & $1,004(8)$ & $9,782(9)$ \\
\hline OAD + insulin & $8,380(9)$ & $954(8)$ & $9,334(9)$ \\
\hline Intensified treatment & $44,042(45)$ & $4,012(56)$ & $48,036(46)$ \\
\hline
\end{tabular}

a $\mathrm{N}(\%)$.

b Mean (SD).

c Median (IQR).

presented in Fig. 1. Patients who did not receive any IT during follow-up had their average glycaemic level below $7 \%(53 \mathrm{mmol} / \mathrm{mol})$ during 2 years post diagnosis, starting with an average $\mathrm{HbA} 1 \mathrm{c}$ level of $7.4 \%(57 \mathrm{mmol} / \mathrm{mol})$ at diagnosis (Fig. 1a). However, patients who receive intensified treatment continued to have average HbA1c trajectory level around $7.5 \%$ (58 $\mathrm{mmol} / \mathrm{mol})$ during 2 years post diagnosis irrespective of the time of treatment intensification (Fig. 1a). Among patients with HbA1c $\geq 7 \%$ ( $\geq 53 \mathrm{mmol} / \mathrm{mol}$ ) consistently during $1 / 2$ year post diagnosis, $29 / 26 \%$ never received any IT during followup. Among those with $\mathrm{HbA} 1 \mathrm{c} \geq 7 \%(\geq 53 \mathrm{mmol} / \mathrm{mol})$ during 1 year post diagnosis, only $40 \%$ received IT before
12 months, and the median time to IT was 16 months (Table 2). In patients with HbAlc $\geq 7 \%$ ( $\geq 53 \mathrm{mmol} /$ mol) consistently during 2 years post diagnosis, only $64 \%$ patients received IT before 2 years of diagnosis, and the median time to IT or receiving at least two OADs was 17 months (mean $=23$ months).

Among patients with $\mathrm{HbA} 1 \mathrm{c} \geq 7.5 \%(\geq 58 \mathrm{mmol} / \mathrm{mol})$ consistently during $1 / 2$ year post diagnosis, $23 / 22 \%$ never received any IT during follow-up. Among those with $\mathrm{HbA} 1 \mathrm{c} \geq 7.5 \%$ ( $\geq 58 \mathrm{mmol} / \mathrm{mol}$ ) during 1 year post diagnosis, only $46 \%$ received IT before 1 year, and the median time to IT or receiving at least two OADs was 14 months (mean 20 months). In patients with HbA1c 

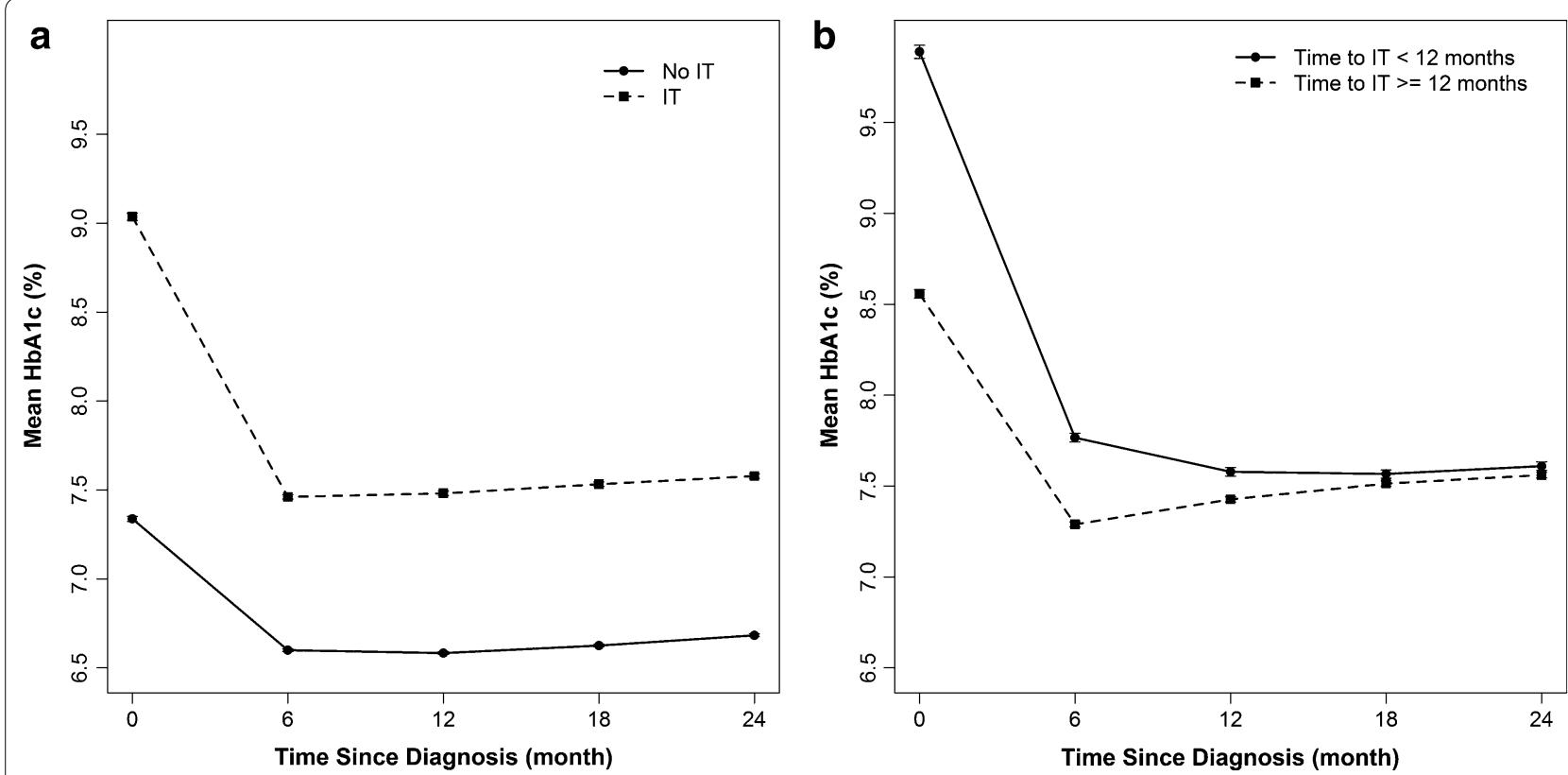

Fig. 1 Six-monthly measure of HbA1c (mean and 95\% Cl) from diagnosis to 2 years, by a patients with and without intensified treatment during follow-up, b by patients receiving treatment intensification before or after 12 months of diagnosis.

Table 2 Proportions of patients with HbA1c above 7 and $7.5 \%$ consistently during 1 year and 2 years post diagnosis of diabetes by categories of time to intensified treatment, and the median (IQR) months to treatment intensifications from diagnosis of diabetes for various classifications of $\mathrm{Hba1c}$ trajectory

\begin{tabular}{|c|c|c|c|c|c|c|}
\hline & \multicolumn{3}{|c|}{ n (\%) by time to intensified treatment categories } & \multicolumn{3}{|c|}{ Time to intensification median (IQR), months } \\
\hline & $<6$ months & $<1$ year & $<2$ years & Time to IT & Time to 2 OADs & Time to 3 ADDs \\
\hline \multicolumn{7}{|l|}{$\mathrm{HbA} 1 \mathrm{c} \geq 7 \%(\geq 53 \mathrm{mmol} / \mathrm{mol})$} \\
\hline Consistently during 1 year & $5,768(27)$ & $8,776(40)$ & $14,101(65)$ & $16(5,32)$ & $17(6,32)$ & $37(20,60)$ \\
\hline Consistently during 2 years & $4,696(28)$ & $6,864(40)$ & $10,904(64)$ & $17(5,31)$ & $17(6,32)$ & $36(20,58)$ \\
\hline \multicolumn{7}{|l|}{$\mathrm{HbA} 1 \mathrm{c} \geq 7.5 \%(\geq 58 \mathrm{mmol} / \mathrm{mol})$} \\
\hline Consistently during 1 year & $3,783(29)$ & $5,869(46)$ & $9,284(72)$ & $14(5,26)$ & $14(5,27)$ & $33(18,54)$ \\
\hline Consistently during 2 years & $2,774(32)$ & $3,999(46)$ & $6,171(70)$ & $14(4,27)$ & $15(5,28)$ & $31(18,52)$ \\
\hline
\end{tabular}

$\geq 7.5 \%$ ( $\geq 58 \mathrm{mmol} / \mathrm{mol})$ consistently during 2 years, $70 \%$ received IT within 2 years post diagnosis. The median/ mean months to IT and 3 ADDs in this group were 14/20 and $31 / 38$ months, respectively.

The distribution of patients with diagnosis of diabetes over different time periods from 1990 to 2012 are presented in Table 1 . The average HbA1c at diagnosis in patients who were diagnosed before 2005, between 2005 and 2009 and from January 2010 onwards were 8.37, 8.02 and $7.81 \%$, respectively, with similar standard deviation of 2.2. Among patients with HbA1c above $7.5 \%$ (58 mmol/mol) consistently over 1 year post diagnosis of diabetes, adjusting for age and baseline $\mathrm{HbA1c}$, patients diagnosed between 2005 and 2009 and from January
2010 onwards were $46 \%$ and $139 \%$ more likely to receive intensified treatment, compared to those who were diagnosed prior to January 2000.

Among patients with HbA1c above 7.5\% (58 mmol/ mol) consistently for 1 year from diagnosis of diabetespatients older than 70 years at diagnosis, with renal disease and with cardiovascular disease were 30\% (95\% CI of odds ratio: $0.63,0.76), 13 \%(95 \% \mathrm{CI}$ of odds ratio: $0.79,0.96)$ and $50 \%$ (95\% CI of odds ratio: $0.45,0.57)$ less likely to receive intensified treatment during follow-up, respectively.

\section{Effect of clinical inertia on cardiovascular risk}

During 5.3 years of median follow-up, the proportions of patients who experienced at least one episode of $\mathrm{MI}$, 
stroke, HF, and any of composite CVE were 2.3, 3.0, 2.2 and $6.8 \%$, respectively. Among those with a history of CVD $(\mathrm{n}=11,955)$, these proportions were $4.8,7.5,4.1$ and $14.4 \%$, respectively. Patients with HbA1c above $7 \%$ (53 $\mathrm{mmol} / \mathrm{mol}$ ) consistently during 1 year post diagnosis had significantly higher rate (per 1,000 person years) of composite CVE [rate $(95 \% \mathrm{CI})$ for $\mathrm{HbA} 1 \mathrm{c} \geq 7 \%$ $(\geq 53 \mathrm{mmol} / \mathrm{mol})$ vs $<7 \%(<53 \mathrm{mmol} / \mathrm{mol}): 1.15(1.10$, $1.20)$ vs $1.04(1.01,1.08)]$. The event rates were similar for those with $\mathrm{HbA} 1 \mathrm{c} \geq 7.5 \%(\geq 58 \mathrm{mmol} / \mathrm{mol})$ during 1 year post diagnosis.

Among all patients, compared to patients with HbA1c below $7 \%$ ( $53 \mathrm{mmol} / \mathrm{mol}$ ) who received IT before 1 year of diagnosis, patients with $\mathrm{HbA1c} \geq 7 \%(\geq 53 \mathrm{mmol} / \mathrm{mol})$ not receiving IT within a year had significantly increased risk of MI, HF, stroke and composite CVE significantly by $67,64,51$ and $62 \%$, respectively, after adjusting for various confounding factors (all p $<0.01$, Table 3). Among patients without history of any CVD $(n=93,522)$, a delay in treatment intensification by 12 months [in conjunction with poor $\mathrm{HbA1c}$ level above $7 \%(53 \mathrm{mmol} / \mathrm{mol})]$ was associated with significantly increased risks for MI, HF, stroke and composite CVE by $80 \%$ (HR CI: 1.45, 2.22), 63\% (HR CI: 1.36, 1.96), 50\% (HR CI: 1.22, 1.84) and 64\% (HR CI: 1.45, 1.85), respectively (all $\mathrm{p}<0.01$ ). Delay in treatment intensification by 12 months in interaction with poor $\mathrm{HbA1c}$ level above $7.5 \%(58 \mathrm{mmol} / \mathrm{mol})$ during 1 year post diagnosis also had similar increased risks for CVE. Among patients with history of CVD prior to diagnosis of diabetes $(n=11,955)$, delay in treatment intensification in conjunction with poor glycaemic control was also significantly associated with increased risk of HF and composite CVE, but not with MI or stroke (Table 3).

Among patients with $\mathrm{HbA} 1 \mathrm{c}$ above $7 \%(53 \mathrm{mmol} / \mathrm{mol})$ consistently during 2 years post diagnosis $(\mathrm{n}=23,101)$, patients who did not receive intensified treatment had 82\% (HR CI: 1.67, 2.10) increased risk of composite CVE. The risk estimates were similar for patients with and without history of cardiovascular diseases. These estimates were obtained after adjusting for all factors mentioned in the method section, except any adjustment for HbA1c levels.

Irrespective of glycaemic control, failure to intensify anti-hyperglycaemic treatments was associated with $42 \%$ (HR CI: $1.21,1.66$ ) and 48\% (HR CI: 1.36, 1.61) significantly increased risk of CVE among patients with and without the history of cardiovascular diseases, respectively.

Subgroup analyses with adjustments for available data on BMI, systolic blood pressure, LDL-cholesterol and total cholesterol at diagnosis revealed similar risks on cardiovascular outcomes, associated with clinical inertia.

\section{Additional analyses on the effects of glycaemic burden} Among patients receiving IT before 12 months, those with HbA1c above $7 \%(53 \mathrm{mmol} / \mathrm{mol})$ and $7.5 \%$ $(58 \mathrm{mmol} / \mathrm{mol}$ ) during 1 year post diagnosis had significantly increased risk of any CVE by $24 \%$ (HR CI: 1.11 , 1.40 ) and $33 \%$ (HR CI: 1.19, 1.50), respectively compared to those with $\mathrm{HbA1c}$ below $7 \%(53 \mathrm{mmol} / \mathrm{mol})$ and $7.5 \%$ $(58 \mathrm{mmol} / \mathrm{mol}$ ) (Table 3). These patients also had significantly increased risks for MI, HF and stroke. Irrespective of the intensity of anti-diabetes drugs and the history of CVD, patients with HbA1c above $7 \%(53 \mathrm{mmol} / \mathrm{mol})$ consistently over 1 year post diagnosis had 21\% (HR CI: $1.15,1.28 ; \mathrm{p}<0.01$ ) increased risk of composite CVE. Among patients without history of CVD, HbA1c above $7 \%(53 \mathrm{mmol} / \mathrm{mol})$ was associated with $22 \%$ increased risk for CVE (HR CI: 1.14, 1.29; p < 0.01).

Male patients, current smokers, and patients who developed renal disease during follow-up had 12, 51, and $43 \%$ increased risk of composite CVE (all p $<0.01$ ), respectively.

\section{Discussion}

Our population level study, based on more than 100,000 newly diagnosed T2DM patients with median 5.3 years of follow-up, reveals that (1) $26 \%$ of patients with HbA1c above $7 \%(53 \mathrm{mmol} / \mathrm{mol})$ during 2 years post diagnosis of diabetes did not receive any intensified treatment for hyperglycaemia during follow-up, (2) 32 and $46 \%$ of patients receiving early treatment intensification within 6 and 12 months of diagnosis continued to have poor glycaemic control over 2 years post diagnosis [HbA1c above $7.5 \%(58 \mathrm{mmol} / \mathrm{mol})]$, (3) a 1 year delay in treatment intensification in conjunction with poor glycaemic control significantly increased the risks of HF, stroke and composite CVE in patients with and without history of CVD before diagnosis of diabetes, and (4) irrespective of early treatment intensification, the glycaemic burden was significantly associated with increased risk of MI, HF, stroke and composite CVE.

In the study cohort $54 \%$ never received any intensified treatment, while their average HbA1c level remained above $6.5 \%(48 \mathrm{mmol} / \mathrm{mol})$, but below $7 \%(53 \mathrm{mmol} /$ mol), during 2 years post diagnosis (Fig. 1a). In the "never intensified" group, the proportions of patients with $\mathrm{HbA} 1 \mathrm{c}$ consistently above $7 \%(53 \mathrm{mmol} / \mathrm{mol})$ and $7.5 \%(58 \mathrm{mmol} / \mathrm{mol})$ during $1 / 2$ years post diagnosis were $15 / 11 \%$ and $7 / 4 \%$, respectively. The median followup time in this group was 4.7 years. The incidence of any CVE in this group was $5.5 \%$ compared to $8.4 \%$ in the IT group.

Earlier observational studies have reported about 3 years of delay in treatment intensification (irrespective of glucose level) [21], high glycaemic burden [HbA1c 
Table 3 Hazard ratios $(95 \% \mathrm{Cl})$ associated with delays in treatment intensification by 1 year in interaction with poor glycaemic control [HbA1C $\geq 7 \%$ ( $\geq 53 \mathrm{mmol} / \mathrm{mol}$ ) and $\mathrm{HbA1C} \geq 7.5 \%$ ( $\geq 58 \mathrm{mmol} / \mathrm{mol})$ ] consistently during 1 year post diagnosis of diabetes for cardiovascular events

\begin{tabular}{|c|c|c|c|c|c|c|}
\hline & $\begin{array}{l}\text { Without previous } \\
\text { CVD HR }(95 \% \mathrm{Cl})\end{array}$ & $\mathbf{P}$ & $\begin{array}{l}\text { With previous } \\
\text { CVD HR }(95 \% \mathrm{Cl})\end{array}$ & $\mathbf{P}$ & $\begin{array}{l}\text { All patients } \\
\text { HR }(95 \% \mathrm{Cl})\end{array}$ & $\mathbf{P}$ \\
\hline \multicolumn{7}{|l|}{$\mathrm{Ml}$} \\
\hline \multicolumn{7}{|c|}{ With $\mathrm{HbA} 1 \mathrm{C} \geq 7 \%(\geq 53 \mathrm{mmol} / \mathrm{mol})$} \\
\hline A: IT within 1 year & $1.37(1.09,1.72)$ & $<0.01$ & $1.21(0.81,1.82)$ & 0.36 & $1.32(1.08,1.61)$ & $<0.01$ \\
\hline B: IT after 1 year & $1.80(1.45,2.22)$ & $<0.01$ & $1.34(0.91,1.96)$ & 0.13 & $1.67(1.39,2.01)$ & $<0.01$ \\
\hline \multicolumn{7}{|c|}{ With $\mathrm{HbA1C} \geq 7.5 \%(\geq 58 \mathrm{mmol} / \mathrm{mol})$} \\
\hline A: IT within 1 year & $1.59(1.27,1.99)$ & $<0.01$ & $1.12(0.73,1.71)$ & 0.62 & $1.47(1.20,1.79)$ & $<0.01$ \\
\hline B: IT after 1 year & $1.56(1.24,1.97)$ & $<0.01$ & $1.42(0.95,2.14)$ & 0.09 & $1.52(1.24,1.86)$ & $<0.01$ \\
\hline \multicolumn{7}{|l|}{ HF } \\
\hline \multicolumn{7}{|c|}{ With $\mathrm{HbA} 1 \mathrm{C} \geq 7 \%(\geq 53 \mathrm{mmol} / \mathrm{mol})$} \\
\hline A: IT within 1 year & $1.14(0.94,1.40)$ & 0.19 & $1.52(1.09,2.12)$ & 0.015 & $1.23(1.04,1.46)$ & 0.017 \\
\hline B: IT after 1 year & $1.63(1.36,1.96)$ & $<0.01$ & $1.66(1.21,2.27)$ & $<0.01$ & $1.64(1.40,1.91)$ & $<0.01$ \\
\hline \multicolumn{7}{|c|}{ With $\mathrm{HbA1C} \geq 7.5 \%(\geq 58 \mathrm{mmol} / \mathrm{mol})$} \\
\hline A: IT within 1 year & $1.32(1.07,1.62)$ & $<0.01$ & $1.52(1.08,2.13)$ & 0.016 & $1.37(1.15,1.63)$ & $<0.01$ \\
\hline B: IT after 1 year & $1.61(1.32,1.97)$ & $<0.01$ & $1.50(1.06,2.12)$ & 0.021 & $1.58(1.33,1.88)$ & $<0.01$ \\
\hline \multicolumn{7}{|l|}{ Stroke } \\
\hline \multicolumn{7}{|c|}{ With $\mathrm{HbA} 1 \mathrm{C} \geq 7 \%(\geq 53 \mathrm{mmol} / \mathrm{mol})$} \\
\hline A: IT within 1 year & $1.28(1.03,1.60)$ & 0.025 & $1.80(1.10,2.95)$ & 0.019 & $1.36(1.12,1.66)$ & $<0.01$ \\
\hline B: IT after 1 year & $1.50(1.22,1.84)$ & $<0.01$ & $1.60(0.98,2.60)$ & 0.06 & $1.51(1.25,1.83)$ & $<0.01$ \\
\hline \multicolumn{7}{|c|}{ With $\mathrm{HbA} 1 \mathrm{C} \geq 7.5 \%(\geq 58 \mathrm{mmol} / \mathrm{mol})$} \\
\hline A: IT within 1 year & $1.27(1.01,1.59)$ & 0.040 & $1.89(1.16,3.06)$ & 0.010 & $1.36(1.11,1.67)$ & $<0.01$ \\
\hline B: IT after 1 year & $1.37(1.09,1.71)$ & $<0.01$ & $1.34(0.78,2.30)$ & 0.28 & $1.36(1.11,1.67)$ & $<0.01$ \\
\hline \multicolumn{7}{|l|}{ Any CVE } \\
\hline \multicolumn{7}{|c|}{ With $\mathrm{HbA} 1 \mathrm{C} \geq 7 \%(\geq 53 \mathrm{mmol} / \mathrm{mol})$} \\
\hline A: IT within 1 year & $1.22(1.07,1.38)$ & $<0.01$ & $1.36(1.06,1.74)$ & 0.015 & $1.24(1.11,1.40)$ & $<0.01$ \\
\hline B: IT after 1 year & $1.64(1.45,1.85)$ & $<0.01$ & $1.57(1.25,1.98)$ & $<0.01$ & $1.62(1.46,1.80)$ & $<0.01$ \\
\hline \multicolumn{7}{|c|}{ With $\mathrm{HbA1C} \geq 7.5 \%(\geq 58 \mathrm{mmol} / \mathrm{mol})$} \\
\hline A: IT within 1 year & $1.32(1.15,1.50)$ & $<0.01$ & $1.40(1.09,1.81)$ & $<0.01$ & $1.33(1.19,1.50)$ & $<0.01$ \\
\hline B: IT after 1 year & $1.50(1.32,1.71)$ & $<0.01$ & $1.50(1.17,1.94)$ & $<0.01$ & $1.50(1.33,1.68)$ & $<0.01$ \\
\hline
\end{tabular}

The reference group was those with TTIT $<12$ months and $\mathrm{HbA} 1 \mathrm{c}<7$ or $7.5 \%$ ( $<53$ or $58 \mathrm{mmol} / \mathrm{mol}$ ). A: TTIT $<12 \mathrm{months}$ and $\mathrm{HbA} 1 \mathrm{c} \geq 7$ or $7.5 \%$ ( $\geq 53$ or $58 \mathrm{mmol} / \mathrm{mol}$ ), B: TTIT $\geq 12$ months and $\mathrm{HbA} 1 \mathrm{c} \geq 7$ or $7.5 \%$ ( $\geq 53$ or $58 \mathrm{mmol} / \mathrm{mol}$ ). Analyses are based on multivariate Cox-regression models, with contrast matrix to evaluate the effect of delay in treatment intensification in conjunction higher and lower levels of $\mathrm{HbA} 1 \mathrm{c}$ at 7 and $7.5 \% \mathrm{cut}$ offs (53 and $58 \mathrm{mmol} / \mathrm{mol}$ ).

$>7.5 \%$ (>58 $\mathrm{mmol} / \mathrm{mol})$ ] for over more than 5 years after the addition of a multiple OADs and insulin $[19,21,34$, 35 , and that it took several years to add insulin after the initiation of 2 OADs [34]. The median (IQR) months to treatment intensification in our study was $21[5,44]$, which is about 12 months less than that reported by Khunti et al. [21]. However, our results are not directly comparable, as the studies were differently designed. In our study those who received IT within 6/12 months of diagnosis had a significant reduction in HbA1c by 2.5/2.3\% within 6 and 12 months post diagnosis (Fig. 1b). Our findings on the failure of intensified treatment to maintain HbA1c within a clinically acceptable limit is broadly in line with those reported in the large surveys conducted in USA and UK [36-39]. However, as no study has yet reported the trajectory of HbA1c with treatment intensification, our unique findings are not directly comparable. The mechanisms of increased risk of macrovascular events with hyperglycaemia are not fully known but may include oxidative stress, inflammation and thrombosis [40-42].

The ACCORD study in patients with 10 years of duration of T2DM could not establish any significant benefit of intensified glucose lowering treatment on macrovascular event during 3.5 years of median follow-up [6]. However, the meta analyses of four major cardiovascular outcome trials in patients with T2DM, including the ACCORD trial data, reported a $15-17 \%$ risk reduction in MI, $15 \%$ risk reduction in coronary heart disease and $9 \%$ risk reduction in major cardiovascular event associated 
with intensive glucose control therapy [9, 43]. While the UKPDS trial was based on newly diagnosed diabetes patients, the median duration of diabetes in the participants of ACCORD, ADVANCE and VADT trials was 9 years, and $34 \%$ of them had history of major cardiovascular disease before randomisation. Findings of our study based on a cohort of patients with new diagnosis of T2DM is broadly in line with the findings of the meta analyses in relation to the beneficial effects of intensified glucose lowering treatments on major cardiovascular risks. The recent cardiovascular outcome trials in established T2DM patients had about 5 years of follow-up and do not provide insight into any longer time benefit in terms of cardiovascular risk. In our cohort with minimum 5 years of follow-up $(n=47,161)$ who continued to have HbA1c above $7 \%$ over 1 year, delay in treatment intensification was associated with $65 \%$ (95\% CI of HR: $1.49,1.84)$ increased risk of CVE-very similar to what we observed in the whole cohort with median 5.3 years of follow-up.

Although early treatment intensification did not reduce the HbA1c below clinically acceptable limit in a significant proportion of patients, the residual benefit of intensified treatment on macrovascular risk is considerable. Compared to patients with HbA1c $<7 \%(<53 \mathrm{mmol} / \mathrm{mol})$ during 1 year post diagnosis, those with $\mathrm{HbA1c} \geq 7 \%$ $(\geq 53 \mathrm{mmol} / \mathrm{mol}$ ) and received IT within a year of diagnosis had 38\% lower risk for any CVE (HR: 1.24) compared to those who had delayed treatment intensification (HR: 1.62, Table 3). Early treatment intensification also showed considerable residual benefits on MI, HF and stroke. This new finding on the residual benefit of intensive anti-diabetes treatment on long-term macrovascular risk, even in patients with continued high glycaemic burden, needs further evaluations with longer term HbA1c trajectory, and other cardiovascular risk factors.

Treatment intensification by insulin and sulfonylurea drugs and its association with cardiovascular and mortality risk was recently evaluated by Roumie et al. [44]. Patients who added insulin to the first line metformin treatment had 30\% significantly higher adjusted risk of composite macrovascular events, compared to those who intensified the treatment by adding sulfonylurea to metformin. In our study about $9 \%$ patients received treatment intensification with insulin, and these patients had higher $\mathrm{HbA1C}$ at diagnosis and during follow-up before intensification, as expected. Patients receiving insulin treatment are generally at higher risk profile, and the finding from Roumie et al. [44] could be partially attributed to this factor. In this study our focus was on glycaemic burden and the failure to intensify anti-hyperglycaemic treatment when deemed necessary. We do however recognise the importance of evaluating therapeutic inertia in a holistic way including cardiovascular risk burden. In our risk analyses, we have adjusted for the use of cardioprotective medications (including anti-hypertensive and lipid lowering drugs) and the risk of renal diseases. We also conducted separate analyses adjusting for available cardiovascular risk factors (weight, blood pressure and cholesterol) in 62,000 patients.

While MI and stroke are relatively well defined hard outcomes with acute onset, HF is a disease of slow onset which develops over time. This introduces the difficulty in defining a correct time of onset, and the likelihood of getting HF detected in the setting of primary care database to a great extent depends on medical attention and on the number of encounters with general practitioners. To account for possible detection bias in this context, we conducted additional analyses with HF confirmed by electrocardiogram analyses, resulting in similar risk estimates for both events.

Patient-level data from electronic databases present challenges in terms of accuracy and completeness of the study variables of interest. The limitations of this study include: (1) the time to treatment intensification was based on the dates of available prescriptions longitudinally, with the likelihood of missing data; (2) non-availability of adherence data on medications; (3) non-availability of prescription on diet and exercise; (4) failure to account for the socio-economic status of the patients, which may well be associated with poor glycaemic control and with an elevated risk of cardiovascular diseases; (5) non-availability of complete and reliable data on alcohol consumption; (6) non-availability of complete and reliable longitudinal data on doses for individual medications, (7) non-availability of hospitalisation data for MI and stroke, and (8) the potential for residual confounding, as common in any clinical epidemiological study. Due to lack of data on longitudinal doses of individual anti-diabetes medications, we could not consider the dose escalation for some anti-diabetes therapies as potential treatment intensification. However, these issues are unlikely to affect the robustness of the results of this study. The large analysis cohort was selected from the validated CPRD database should be considered as a representative sample, and as such, provides a good picture of the state of diabetes control in routine practice. Apart from complete data on demographics, we had complete data on $\mathrm{HbA1c}$ measured within 3-month window of diagnosis of diabetes. The 6-monthly follow-up measures of HbAlc were imputed for only $9 \%$ missing cases with random missing pattern. Finally, careful design of the study by defining sensible exposure time, time line for events, and appropriate adjustments for various aspects while determining the time-to-events are the primary strengths of the study. 


\section{Conclusions}

As with all observational studies, we were unable to provide definitive evidence for direct cause-effect relationships, and the risks of false positive or negative findings due to selection bias and residual confounding, even after the most stringent corrections, may not be trivial. However, although the results from large controlled clinical trials evaluating the effect of intensified glucose lowering treatment on macrovascular complications in patients with T2DM have been inconclusive, our longitudinal study with primary care level data demonstrates the beneficial effect of guideline recommended tight glycaemic targets on long-term cardiovascular risks.

\begin{abstract}
Abbreviations
ADD: anti-diabetes drug; BMI: Body mass index; Cl: confidence interval; CPRD: Clinical Practice Research Database; CVE: macrovascular event; HbA1c: haemoglobin A1C; HF: heart failure; HR: hazard ratio; INS: insulin; IT: treatment intensification; MI: myocardial infarction; OAD: oral antidiabetes drug; OR: odds ratio; T2DM: type 2 diabetes; TTIT: time to treatment intensification.
\end{abstract}

\section{Authors' contributions}

SKP and KK conceived the idea of the study. SKP and Kere $K$ were responsible for the design of the study. KK, BLT and MLW assisted with the design of the study. Kere K developed the complex programming codes to create analysis data from the relational database. BLT and MLW defined the Read Codes and the ICD-9 codes from the database. SKP conducted the analyses. The initial draft of the manuscript was prepared by SKP, and then circulated amongst all authors for critical revision. SKP is the guarantor of this work and, as such, had full access to all the data in the study and takes responsibility for the integrity of the data and the accuracy of the data analysis. All authors read and approved the final manuscript.

\section{Author details}

${ }^{1}$ Clinical Trials and Biostatistics Unit, QIMR Berghofer Medical Research Institute, 300 Herston Road, Herston, Brisbane, QLD 4006, Australia. ${ }^{2}$ Novo Nordisk A/S, Vandtårnsvej, Denmark. ${ }^{3}$ Leicester Diabetes Centre, University of Leicester, Leicester, UK.

\section{Acknowledgements}

The QIMR Berghofer Medical Research Institute is grateful for support from UKCPRD, Novo Nordisk A/S and an infrastructure research grant from the Australian Government Department of Education's National Collaborative Research Infrastructure Strategy initiative through Therapeutic Innovation Australia. The Leicester Diabetes Research Centre, University of Leicester is grateful for support from the NIHR Collaboration for Leadership in Applied Health Research and Care East Midlands (CLAHRC-EM). The interpretation and conclusions contained in this study are those of the authors alone.

\section{Compliance with ethical guidelines}

\section{Competing interests}

All authors have completed the Unified Competing Interest form at http:// www.icmje.org/coi_disclosure.pdf (available on request from the corresponding author) and declare that (1) SP, Kere K, KK have support from QIMR Berghofer Medical Research Institute and University of Leicester (United Kingdom) for the submitted work; (2) BLT and MLW are employees of Novo Nordisk A/S, (3) SP has acted as a consultant and speaker for Novartis and Amylin Pharmaceuticals LLC. He has received grants in support from investigator and investigator initiated clinical studies from Merck, Bristol-Myers Squibb, Novo Nordisk and Pfizer. KK has acted as a consultant and speaker for Novartis, Novo Nordisk, Sanofi-Aventis, Jansen, Boehringer Ingelheim, Lilly and Merck Sharp and Dohme. He has received grants in support for investigator and investigator initiated trials from Novartis, Novo Nordisk, Sanofi-Aventis, Lilly,
Pfizer, Boehringer Ingelheim and Merck Sharp and Dohme; (4) their spouses, partners, or children have no financial relationships that may be relevant to the submitted work; and (5) the authors have no nonfinancial interests that may be relevant to the submitted work.

Received: 18 June 2015 Accepted: 18 July 2015

Published online: 07 August 2015

\section{References}

1. International Diabetes Federation (ed) (2014) IDF diabetes atlas, 6th edn International Diabetes Federation, Brussels, Belgium

2. UK Prospective Diabetes Study (UKPDS) Group (1998) Effect of intensive blood-glucose control with metformin on complications in overweight patients with type 2 diabetes (UKPDS 34). Lancet 352:854-865

3. Patel A, MacMahon S, Chalmers J, Neal B, Billot L, Woodward M et al (2008) Intensive blood glucose control and vascular outcomes in patients with type 2 diabetes. N Engl J Med 358:2560-2572

4. Skyler JS, Bergenstal R, Bonow RO, Buse J, Deedwania P, Gale EAM et al (2009) Intensive glycemic control and the prevention of cardiovascular events: implications of the ACCORD, ADVANCE, and VA diabetes trials. A position statement of the American Diabetes Association and a Scientific Statement of the American College of Cardiology Foundation and the American Heart Association. J Am Coll Cardiol 53:298-304

5. Del Prato S (2009) Megatrials in type 2 diabetes. From excitement to frustration? Diabetologia 52:1219-1226

6. Ismail-Beigi F, Craven T, Banerji MA, Basile J, Calles J, Cohen RM et al (2010) Effect of intensive treatment of hyperglycaemia on microvascular outcomes in type 2 diabetes: an analysis of the ACCORD randomised trial. Lancet 376:419-430

7. Griffin SJ, Borch-Johnsen K, Davies MJ, Khunti K, Rutten GEHM, Sandbæk A et al (2011) Effect of early intensive multifactorial therapy on 5-year cardiovascular outcomes in individuals with type 2 diabetes detected by screening (ADDITION-Europe): a cluster-randomised trial. Lancet 378:156-167

8. Holman RR, Paul SK, Bethel MA, Matthews DR, Neil HA (2008) 10-year follow-up of intensive glucose control in type 2 diabetes. N Engl J Med 359:1577-1589

9. Turnbull FM, Abraira C, Anderson RJ, Byington RP, Chalmers JP, Duckworth WC et al (2009) Intensive glucose control and macrovascular outcomes in type 2 diabetes. Diabetologia 52:2288-2298

10. Nathan DM, Buse JB, Davidson MB, Ferrannini E, Holman RR, Sherwin R et al (2009) Medical management of hyperglycemia in type 2 diabetes: a consensus algorithm for the initiation and adjustment of therapy. Diabetes Care 32:193-203

11. Raz I, Riddle MC, Rosenstock J, Buse JB, Inzucchi SE, Home PD et al (2013) Personalized management of hyperglycemia in type 2 diabetes: reflections from a Diabetes Care Editors' Expert Forum. Diabetes Care 36:1779-1788

12. Scheen AJ, Mathieu C (2012) Management of hyperglycaemia in type 2 diabetes: a patient-centered approach. Rev Med Liege 67:623-631

13. American Diabetes Association (2015) Standards of medical care in diabetes. Diabetes Care 38(Supplement 1):S4

14. Muhlhauser I, Meyer G (2013) Evidence base in guideline generation in diabetes. Diabetologia 56:1201-1209

15. American Diabetes Association (2014) Standards of medical care in diabetes-2014. Diabetes Care 37:S14-S80

16. NICE (2009) Type 2 diabetes: the management of type 2 diabetes: NICE clinical guideline 87. National Institute for Health and Care Excellence, London, UK

17. Yam FK, Adams AG, Divine H, Steinke D, Jones MD (2013) Clinical inertia in type 2 diabetes: a retrospective analysis of pharmacist-managed diabetes care vs. usual medical care. Pharm Prac 11:203-210

18. Coan KE, Schlinkert AB, Beck BR, Haakinson DJ, Castro JC, Apsey HA et al (2013) Clinical inertia during postoperative management of diabetes mellitus: relationship between hyperglycemia and insulin therapy intensification. J Diabetes Sci Technol 7:880-887

19. Mata-Cases M, Benito-Badorrey B, Roura-Olmeda P, Franch-Nadal J, Pepio-Vilaubi JM, Saez M et al (2013) Clinical inertia in the treatment of hyperglycemia in type 2 diabetes patients in primary care. Curr Med Res Opin 29:1495-1502 
20. Gil-Guillen V, Orozco-Beltran D, Carratala-Munuera C, Marquez-Contreras E, Durazo-Arvizu R, Cooper R et al (2013) Clinical inertia in poorly controlled elderly hypertensive patients: a cross-sectional study in Spanish physicians to ascertain reasons for not intensifying treatment. Am J Cardiovasc Drugs Drugs Dev Other Interv 13:213-219

21. Khunti K, Wolden ML, Thorsted BL, Andersen M, Davies MJ (2013) Clinical inertia in people with type 2 diabetes: a retrospective cohort study of more than 80,000 people. Diabetes Care 36:3411-3417

22. Penno G, Solini A, Zoppini G, Orsi E, Fondelli C, Zerbini G et al (2013) Hemoglobin A(1c) variability as an independent correlate of cardiovascular disease in patients with type 2 diabetes: a cross-sectional analysis of the Renal Insufficiency and Cardiovascular Events (RIACE) Italian Multicenter Study. Cardiovasc Diabetol 12:98

23. Sidorenkov G, Voorham J, de Zeeuw D, Haaijer-Ruskamp FM, Denig P (2013) Do treatment quality indicators predict cardiovascular outcomes in patients with diabetes? PLOS ONE 8(10):e78821

24. Asche CV, Bode B, Busk AK, Nair SR (2012) The economic and clinical benefits of adequate insulin initiation and intensification in people with type 2 diabetes mellitus. Diabetes Obes Metab 14(1):47-57

25. Majeed A (2004) Sources, uses, strengths and limitations of data collected in primary care in England. Health Stat Q 21:5-14

26. Khan NF, Harrison S, Rose P (2010) Validity of diagnostic coding within the General Practice Research Database: a systematic review. Br J Gen Prac 60(129):e128-e136

27. Williams T, Van Staa T, Puri S, Eaton S (2012) Recent advances in the utility and use of the General Practice Research Database as an example of a UK Primary Care Data resource. Ther Adv Drug Saf 3:89-99

28. Tate AR, Beloff N, Al-Radwan B, Wickson J, Puri S, Williams T et al (2014) Exploiting the potential of large databases of electronic health records for research using rapid search algorithms and an intuitive query interface. J Am Med Inform Association 21:292-298

29. MacDonald MR, Eurich DT, Majumdar SR, Lewsey JD, Bhagra S, Jhund PS et al (2010) Treatment of type 2 diabetes and outcomes in patients with heart failure: a nested case-control study from the U.K. General Practice Research Database. Diabetes Care 33:1213-1218

30. Sadek AR, van Vlymen J, Khunti K, de Lusignan S (2012) Automated identification of miscoded and misclassified cases of diabetes from computer records. Diabetic Med 29:410-414

31. De Lusignan S, Khunti K, Belsey J, Hattersley A, Van Vlymen J, Gallagher H et al (2010) A method of identifying and correcting miscoding, misclassification and misdiagnosis in diabetes: a pilot and validation study of routinely collected data. Diabetic Med 27:203-209

32. Yuan YC (2010) Multiple imputation for missing data: concepts and new developments (version 9.0). SAS Institute Inc, Rockville
33. Thomas G, Klein K, Paul S (2014) Statistical challenges in analysing large longitudinal patient-level data: the danger of misleading clinical inferences with imputed data. J Indian Soc Agric Stat 68:39-54

34. Owens DR (2013) Clinical evidence for the earlier initiation of insulin therapy in type 2 diabetes. Diabetes Technol Ther 15:776-785

35. Kuusisto J, Mykkanen L, Pyorala K, Laakso M (1994) NIDDM and its metabolic control predict coronary heart disease in elderly subjects. Diabetes 43:960-967

36. Zafar A, Davies M, Azhar A, Khunti K (2010) Clinical inertia in management of T2DM. Primary Care Diabetes 4:203-207

37. Ford ES, Li C, Little RR, Mokdad AH (2008) Trends in A1C concentrations among U.S. adults with diagnosed diabetes from 1999 to 2004. Diabetes Care 31:102-104

38. Strain WD, Bluher M, Paldanius PM (2013) 2013 expectations and aspirations of elderly patients and physicians with type 2 diabetes. International Diabetes Federation's World Diabetes Congress 2013 Dec 5 2013, Melbourne, Australia

39. Health and Social Care Information Centre (2013) National diabetes audit-2011-12. http://www.hscic.gov.uk/catalogue/PUB12421. Accessed 29 Dec 2014

40. Mohanty P, Hamouda W, Garg R, Aljada A, Ghanim H, Dandona P (2000) Glucose challenge stimulates reactive oxygen species (ROS) generation by leucocytes. J Clin Endocrinol Metab 85:2970-2973

41. Aljada A (2003) Endothelium, inflammation, and diabetes. Metab Syndr Relat Disord 1:3-21

42. Dhindsa S, Tripathy D, Mohanty P, Ghanim H, Syed T, Aljada A et al (2004) Differential effects of glucose and alcohol on reactive oxygen species generation and intranuclear nuclear factor-kappaB in mononuclear cells. Metab, Clin Exp 53:330-334

43. Ray KK, Seshasai SRK, Wijesuriya S, Sivakumaran R, Nethercott S, Preiss D et al (2009) Effect of intensive control of glucose on cardiovascular outcomes and death in patients with diabetes mellitus: a meta-analysis of randomised controlled trials. Lancet 373:1765-1772

44. Roumie CL, Greevy RA, Grijalva CG, Hung AM, Liu X, Murff HJ et al (2014) Association between intensification of metformin treatment with insulin vs sulfonylureas and cardiovascular events and all-cause mortality among patients with diabetes. JAMA 311(22):2288-2296

\section{Submit your next manuscript to BioMed Central and take full advantage of:}

- Convenient online submission

- Thorough peer review

- No space constraints or color figure charges

- Immediate publication on acceptance

- Inclusion in PubMed, CAS, Scopus and Google Scholar

- Research which is freely available for redistribution

Submit your manuscript at

www.biomedcentral.com/submit

C BioMed Central 